\title{
Kathleen BURK, Troublemaker: The Life and History of A.J.P. Taylor
}

New Haven : Yale University Press, 2000

\section{François Poirier}

\section{OpenEdition Journals}

Édition électronique

URL : http://journals.openedition.org/rfcb/3467

DOI : $10.4000 /$ rfcb.3467

ISSN : 2429-4373

Éditeur

CRECIB - Centre de recherche et d'études en civilisation britannique

\section{Édition imprimée}

Date de publication : 1 avril 2005

ISBN : 2-911580-20-6

ISSN : 0248-9015

\section{Référence électronique}

François Poirier, « Kathleen BURK, Troublemaker: The Life and History of A.J.P. Taylor », Revue Française de Civilisation Britannique [En ligne], XIII-2 | 2005, mis en ligne le 01 avril 2005, consulté le 23 septembre 2020. URL : http://journals.openedition.org/rfcb/3467 ; DOI : https://doi.org/10.4000/rfcb. 3467

Ce document a été généré automatiquement le 23 septembre 2020

Revue française de civilisation britannique est mis à disposition selon les termes de la licence Creative Commons Attribution - Pas d'Utilisation Commerciale - Pas de Modification 4.0 International. 


\section{Kathleen BURK, Troublemaker: The Life and History of A.J.P. Taylor}

New Haven : Yale University Press, 2000

François Poirier

\section{RÉFÉRENCE}

Kathleen BURK, Troublemaker : The Life and History of A.J.P. Taylor, New Haven : Yale University Press, 2000, xiv+491 p. ISBN 0-300-09453-1

1 À quoi peut bien servir la biographie d'un historien qui fut très actif, mais reste dépourvu de l'aura de l'épopée ou de l'aventure et qui a déjà composé son autobiographie? Eh bien pour commencer à rappeler ce que l'historien en question, A.J.P. Taylor (1906-1990) recommandait lui-même: se méfier des sources autobiographiques. Maint chapitre est l'occasion d'une déconstruction du discours autobiographique lequel, confronté à une multitude de sources, révèle tous ses biais, toute sa part de réinvention. Mais que nous importe Taylor? L'historien est sans conteste le plus populaire du $\mathrm{XX}^{\mathrm{e}}$ siècle et a su vulgariser, dans les médias les plus modernes, une conception de l'identité historique de la Grande-Bretagne - ou peut-être simplement de l'Angleterre - qui a influencé deux ou trois générations. Ce n'était pas un théoricien, mais un historien talentueux qui savait trouver les formules qui frappent l'imagination du lecteur ou de l'auditeur. Ce n'était pas non plus un isolé de génie, mais un bon produit de la société de son temps.

2 C'est pourquoi l'ouvrage ne manque jamais d'évoquer en courtes vignettes des éléments biographiques sur tous ceux qu'a côtoyés A.J.P. Taylor. Au début, on en est un peu agacé, avec le sentiment qu'il s'agit d'un simple exercice d'érudition amusante. Tant de ces figures sont à présent oubliées que leur résurrection ne déclenche aucun enthousiasme. Mais on s'aperçoit bientôt que c'est justement là que le travail de Kathleen Burk répond à d'autres préoccupations qu'avait exprimées Taylor dans des aphorismes rappelés en épigraphe. Taylor aimait lire des biographies parce qu'elles 
s'attachent à l'humain, mais préférait écrire de l'histoire, avec ses généralisations parfois désincarnées, ses interprétations parfois abstraites. C'est sans doute pour compenser ce risque de sécheresse que sa façon d'écrire l'histoire s'animait d'anecdotes et de menues illustrations bien vivantes. Mais avec ces vignettes sur des personnages dont beaucoup sont devenus - ou restés -secondaires, K. Burk retrace en fait l'atmosphère d'une époque et l'histoire culturelle sans laquelle celle de la formation intellectuelle d'un historien parmi d'autres ne serait ni possible, ni intéressante. Ainsi voit-on se constituer des réseaux dans le microcosme oxonien, par exemple - l'étude des réseaux pouvant être, soit dit en passant, un parfait moyen terme entre l'individualisme de la démarche biographique et les forces collectives aveugles d'une certaine histoire sociale. On tient ici le paradoxe qui fait la saveur du livre: une biographie ne peut s'attacher qu'à un personnage haut en couleur et à sa façon de sage universitaire, Taylor en était un sans conteste. Mais l'histoire s'intéresse à la collectivité, avec ses personnages ordinaires. Montrer la relation du personnage principal avec tous ces comparses, choisis ou imposés par les circonstances, et dont certains pouvaient rivaliser avec lui tandis que d'autres restaient fondus dans la masse, c'est, d'une certaine façon, tracer les limites de l'exercice biographique ordinaire et l'insérer dans l'histoire.

3 Il existe en France une tradition dans laquelle le biographe est libre d'imaginer des scènes dont rien n'atteste qu'elles ont eu lieu, mais que l'interprétation de l'auteur rend plausibles. C'est parfois tout à fait stimulant, comme en témoigne la réputation et le succès qu'a rencontrés Jean Orieux. Rien de tel ici, s'agissant de Taylor, où lorsqu'il y a lieu de spéculer, c'est en présence de sources contradictoires, ou bien de l'incrédulité que suscite le récit de Taylor lui-même. Plus que d'une biographie, il s'agit donc d'une contribution à l'histoire intellectuelle du Royaume-Uni qui tente de ne rien laisser dans l'ombre - pas même les circonstances matérielles des purs esprits, avec un excellent chapitre final sur la façon qu'avait Taylor de négocier et de gérer les revenus de son activité. S'il paraît souvent difficile d'initier les étudiants à la dimension historiographique du débat identitaire qui agite aujourd'hui le Royaume-Uni, peut-être est-il plus aisé de le faire en s'appuyant sur l'étude d'itinéraires comme celui d'A.J.P. Taylor - un itinéraire avec ses croisées de chemins, ses détours, ses rencontres.

\section{AUTEURS}

\section{FRANÇOIS POIRIER}

Université Paris 13 